D0I: 10.12957/demetra.2015.16721

\title{
Boas práticas na manipulação de alimentos em Unidades de Alimentação e Nutrição
}

\section{Good Practices of food handling in Food and Nutrition Services}

Lauriete Carlos Silva'

Daniele Barboza dos Santos'

Jackline Freitas Brilhante de São José ${ }^{1}$

Erika Madeira Moreira da Silva'

1 Universidade Federal do Espírito Santo, Departamento de Educação Integrada em Saúde, Curso de Nutrição. Vitória- ES, Brasil.

Correspondência / Correspondence Jackline Freitas Brilhante de São José Departamento de Educação Integrada em Saúde, Universidade Federal do Espírito Santo Av. Marechal Campos, 1468, Maruípe, Vitória-ES, Brasil. CEP 29040-090

E-mail: jackline.jose@ufes.br

\section{Resumo}

$\mathrm{O}$ presente estudo visou diagnosticar o atendimento às boas práticas de manipulação em duas unidades de alimentação e nutrição (UAN) localizadas no município de Vitória-ES. Para a avaliação do atendimento às boas práticas de manipulação, foi utilizada uma lista de verificação proposta pela RDC n ${ }^{\circ} 216$ da Agência Nacional de Vigilância Sanitária, dividida em três partes: identificação da empresa, avaliação e classificação do estabelecimento. Em relação ao atendimento aos itens propostos na lista de verificação, o percentual de adequação na unidade 1 foi de $71,81 \%$ e na unidade 2 foi $76,36 \%$, sendo classificados no grupo 2 e grupo 1, respectivamente. Dentre as inadequações evidenciadas em ambos os estabelecimentos, destacam-se os itens relacionados a: edificações, móveis e utensílios; manipuladores; armazenamento e transporte do alimento preparado e exposição ao consumo do alimento preparado. Nota-se que a presença do responsável técnico capacitado é de extrema importância para a realização e manutenção das boas práticas de higiene e que a aplicação de uma ferramenta simples, como a lista de verificação, permite avaliar as condições higiênico-sanitárias de unidades que preparam refeições e, a partir das observações, buscar estratégias para corrigir as falhas evidenciadas.

Palavras-chave: Boas Práticas de Fabricação. Serviços de Alimentação. Qualidade dos Alimentos. Manipulação de Alimentos. 


\section{Abstract}

This study aimed to assess the requirements of the good manufacturing practices in two food and nutrition services located in Vitoria-ES, Brazil. For the assessment of compliance with good manufacturing practices, it was used a checklist proposed by RDC No. 216 of the National Health Surveillance Agency, divided into three parts: company identification, evaluation and classification of the establishment. Regarding compliance to the proposed items on the checklist, the adequacy percentage in the unit 1 was $71.81 \%$ and unit 2 was $76.36 \%$, classified in group 2 and group 1, respectively. Among the inadequacies highlighted in both establishments, it can be pointed out: buildings (structure), furniture and fixtures; handlers; storage and transportation of food prepared and exposure to consumption of prepared food. It is important to highlight that the presence of a qualified responsible technician is extremely important for the achievement and maintenance of good hygiene practices. The application of a simple tool like the checklist allows evaluating the hygienicsanitary conditions of units that prepare and serve meals and from observations, seek strategies to correct the evident failures.

Key words: Good Manufacturing Practices. Food Service. Food Quality. Food Handling.

\section{Introdução}

O consumo de alimentos fora de casa, seja por questões sociais ou por necessidades vinculadas a rotina e estilo de vida atual, tem contribuído para o crescimento dos serviços de alimentação. Com o aumento no número de refeições oferecidas fora do lar, torna-se grande a preocupação com a qualidade dos alimentos oferecidos aos usuários. Milhões de pessoas são diretamente afetadas por doenças de origem alimentar (DOA) em todo o mundo e as doenças causadas pelo consumo de alimentos contaminados são consideradas um grave problema de saúde no mundo atual. ${ }^{1}$

De acordo com a estimativa para o ano de 2014 pela Associação Brasileira de Refeições Coletivas, o mercado de refeições coletivas como um todo forneceu mais de 12 milhões de refeições/dia, movimentando uma cifra de mais 18,8 bilhões de reais por ano e com um volume diário de 5,7 mil toneladas de alimentos utilizados. ${ }^{2}$ 
Dentre as modalidades de serviços de alimentação, destacam-se as unidades de alimentação e nutrição (UAN), considerada a unidade de trabalho ou órgão de uma empresa que desempenha atividades relacionadas à alimentação e à nutrição, independentemente da situação que ocupa na escala hierárquica da entidade. ${ }^{3}$ Esses estabelecimentos são largamente frequentados pela população, com o intuito de obter uma alimentação mais segura. A procura está relacionada ao reconhecimento, por parte dos usuários, que acreditam na qualidade relacionada aos aspectos nutricionais e sensoriais dos alimentos, à segurança em relação às condições higiênico-sanitárias, ao atendimento realizado pelos fornecedores e ao valor cobrado. Uma das estratégias para se atingir um alto padrão de qualidade é a implementação das Boas Práticas de Manipulação dos alimentos, que têm como objetivo estabelecer procedimentos adequados para contribuir com as condições higiênico-sanitárias dos alimentos preparados em serviços de alimentação., ${ }^{4,5}$

Nas UANs, os alimentos podem estar suscetíveis a diferentes fontes de contaminações por microorganismos relacionados à manipulação e aos procedimentos inadequados durante o processamento e distribuição. Para garantir alimentos mais seguros, ferramentas de controle como as boas práticas e análise de perigos e pontos críticos de controle (APPCC) têm sido amplamente utilizadas. ${ }^{6}$

A garantia da segurança dos alimentos tem sido discutida e, assim, estudos sobre condições higiênicas e práticas de manipulação e preparo de alimentos são pertinentes. A lista de verificação é uma ferramenta que permite fazer uma avaliação preliminar das condições higiênico-sanitárias de um estabelecimento produtor de refeições. A avaliação inicial permite identificar as não conformidades e, a partir dos dados coletados, propor medidas corretivas para adequação das condições de preparo das refeições.

Diante da importância do tema para a saúde de coletividades, o presente estudo visou diagnosticar o atendimento às boas práticas de manipulação em UANs localizadas no município de Vitória-ES.

\section{Material e métodos}

Em julho de 2013, foi conduzido um estudo transversal em duas UANs localizadas no município de Vitória-ES. Inicialmente, os responsáveis pelos estabelecimentos foram contatados por meio de carta-convite para apresentação dos objetivos da pesquisa e foi solicitada a permissão para visita e avaliação.

Para a avaliação do atendimento às boas práticas de manipulação, foi utilizada uma lista de verificação proposta pela Resolução da Agência Nacional de Vigilância Sanitária - ANVISA RDC n ${ }^{\circ}$ 216/2004, ${ }^{7}$ dividida em três partes: identificação da empresa, avaliação e classificação do estabelecimento. A lista de verificação apresenta 11 blocos de perguntas avaliados em cada unidade, totalizando 90 itens, conforme o quadro 1. 
Quadro 1. Blocos e itens presentes na lista de verificação de boas práticas de manipulação de alimentos. Vitória-ES, 2013.

\begin{tabular}{|c|c|}
\hline BLOCOS & ITENS \\
\hline \multirow{8}{*}{$\begin{array}{l}\text { EDIFICAÇÕES } \\
\text { E } \\
\text { INSTALAÇÕES }\end{array}$} & $\begin{array}{l}\text { São projetadas de forma a possibilitar um fluxo ordenado e sem } \\
\text { cruzamentos em todas as etapas da preparação de alimentos e a facilitar } \\
\text { as operações de manutenção, limpeza e, quando for o caso, desinfecção. } \\
\text { O acesso às instalações é controlado e independente, não comum a } \\
\text { outros usos. }\end{array}$ \\
\hline & $\begin{array}{l}\text { O dimensionamento da edificação e das instalações é compatível com } \\
\text { todas as operações. Existe separação entre as diferentes atividades } \\
\text { por meios físicos ou por outros meios eficazes de forma a evitar a } \\
\text { contaminação cruzada. }\end{array}$ \\
\hline & $\begin{array}{l}\text { As instalações físicas como piso, parede e teto possuem revestimento liso, } \\
\text { impermeável e lavável. Pisos, paredes e teto são íntegros, conservados, } \\
\text { livres de rachaduras, trincas, goteiras, vazamentos, infiltrações, bolores, } \\
\text { descascamentos, dentre outros e não devem transmitir contaminantes } \\
\text { aos alimentos. }\end{array}$ \\
\hline & $\begin{array}{l}\text { As portas e as janelas são ajustadas aos batentes. As portas da área de } \\
\text { preparação e armazenamento de alimentos são dotadas de fechamento } \\
\text { automático. As aberturas externas das áreas de armazenamento e } \\
\text { preparação de alimentos são providas de telas milimetradas para impedir } \\
\text { o acesso de vetores e pragas urbanas. As telas são removíveis para facilitar } \\
\text { a limpeza periódica. }\end{array}$ \\
\hline & $\begin{array}{l}\text { As instalações são abastecidas de água corrente e dispõem de conexões } \\
\text { com rede de esgoto ou fossa séptica. Os ralos são sifonados e as grelhas } \\
\text { possuem dispositivo que permite seu fechamento. }\end{array}$ \\
\hline & $\begin{array}{l}\text { As caixas de gordura e de esgoto possuem dimensão compatível ao } \\
\text { volume de resíduos, devendo estar localizadas fora da área de preparação } \\
\text { e armazenamento de alimentos e apresentam adequado estado de } \\
\text { conservação e funcionamento. }\end{array}$ \\
\hline & $\begin{array}{l}\text { As áreas internas e externas do estabelecimento são livres de objetos em } \\
\text { desuso ou estranhos ao ambiente, não havendo presença de animais. }\end{array}$ \\
\hline & $\begin{array}{l}\text { A iluminação da área de preparação proporciona a visualização de } \\
\text { forma que as atividades são realizadas sem comprometer a higiene e as } \\
\text { características sensoriais dos alimentos. As luminárias localizadas sobre } \\
\text { a área de preparação dos alimentos são apropriadas e estão protegidas } \\
\text { contra explosão e quedas acidentais. }\end{array}$ \\
\hline
\end{tabular}




\begin{tabular}{|c|c|}
\hline \multirow{8}{*}{$\begin{array}{l}\text { EDIFICAÇÕES } \\
\text { E } \\
\text { INSTALAÇÕES }\end{array}$} & $\begin{array}{l}\text { As instalações elétricas são embutidas ou protegidas em tubulações } \\
\text { externas e íntegras, de forma a permitir a higienização dos ambientes. }\end{array}$ \\
\hline & $\begin{array}{l}\text { A ventilação garante a renovação do ar e a manutenção do ambiente livre } \\
\text { de fungos, gases, fumaça, pós, partículas em suspensão, condensação de } \\
\text { vapores dentre outros que possam comprometer a qualidade higiênico- } \\
\text { sanitária do alimento. O fluxo de ar não incide diretamente sobre os } \\
\text { alimentos. }\end{array}$ \\
\hline & $\begin{array}{l}\text { Os equipamentos e os filtros para climatização são conservados. A } \\
\text { limpeza dos componentes do sistema de climatização, a troca de filtros e a } \\
\text { manutenção programada e periódica destes equipamentos são registradas } \\
\text { e realizadas conforme legislação específica. }\end{array}$ \\
\hline & $\begin{array}{l}\text { As instalações sanitárias e os vestiários não se comunicam diretamente } \\
\text { com a área de preparação e armazenamento de alimentos ou refeitórios, } \\
\text { sendo mantidos organizados e em adequado estado de conservação. As } \\
\text { portas externas são dotadas de fechamento automático. }\end{array}$ \\
\hline & $\begin{array}{l}\text { As instalações sanitárias possuem lavatórios e estão supridas de produtos } \\
\text { destinados à higiene pessoal, tais como papel higiênico, sabonete líquido } \\
\text { inodoro anti-séptico ou sabonete líquido inodoro e produto anti-séptico } \\
\text { e toalhas de papel não reciclado ou outro sistema higiênico e seguro } \\
\text { para secagem das mãos. Os coletores dos resíduos são dotados de tampa } \\
\text { e acionados sem contato manual. }\end{array}$ \\
\hline & $\begin{array}{l}\text { Existem lavatórios exclusivos para a higiene das mãos na área de } \\
\text { manipulação, em posições estratégicas em relação ao fluxo de preparo } \\
\text { dos alimentos e em número suficiente, de modo a atender toda a área de } \\
\text { preparação. Os lavatórios possuem sabonete líquido inodoro anti-séptico } \\
\text { ou sabonete líquido inodoro e produto anti-séptico, toalhas de papel não } \\
\text { reciclado ou outro sistema higiênico e seguro de secagem das mãos e } \\
\text { coletor de papel, acionado sem contato manual. }\end{array}$ \\
\hline & $\begin{array}{l}\text { Os equipamentos, móveis e utensílios que entram em contato com } \\
\text { alimentos são de materiais que não transmitam substâncias tóxicas, } \\
\text { odores, nem sabores aos mesmos, conforme estabelecido em legislação } \\
\text { específica. São mantidos em adequando estado de conservação e ser } \\
\text { resistentes à corrosão e a repetidas operações de limpeza e desinfecção. }\end{array}$ \\
\hline & $\begin{array}{l}\text { São realizadas manutenção programada e periódica dos equipamentos } \\
\text { e utensílios e calibração dos instrumentos ou equipamentos de medição, } \\
\text { mantendo registro da realização dessas operações. }\end{array}$ \\
\hline
\end{tabular}




\begin{tabular}{|c|c|}
\hline & $\begin{array}{l}\text { As superfícies dos equipamentos, móveis e utensílios utilizados na } \\
\text { preparação, embalagem, armazenamento, transporte, distribuição e } \\
\text { exposição à venda dos alimentos são lisas, impermeáveis, laváveis e } \\
\text { estão isentas de rugosidades, frestas e outras imperfeições que possam } \\
\text { comprometer a higienização dos mesmos e serem fontes de contaminação } \\
\text { dos alimentos. }\end{array}$ \\
\hline & $\begin{array}{l}\text { As instalações, os equipamentos, os móveis e os utensílios são mantidos } \\
\text { em condições higiênico-sanitárias apropriadas. }\end{array}$ \\
\hline & $\begin{array}{l}\text { As operações de higienização são realizadas por funcionários } \\
\text { comprovadamente capacitados e com frequência que garanta a } \\
\text { manutenção dessas condições e minimize o risco de contaminação do } \\
\text { alimento. }\end{array}$ \\
\hline & $\begin{array}{l}\text { As caixas de gordura são periodicamente limpas. O descarte dos resíduos } \\
\text { atende ao disposto em legislação específica. }\end{array}$ \\
\hline & $\begin{array}{l}\text { As operações de limpeza e, se for o caso, de desinfecção das instalações e } \\
\text { equipamentos, quando não são realizadas rotineiramente, são registradas. }\end{array}$ \\
\hline & $\begin{array}{l}\text { A área de preparação dos alimentos é higienizada imediatamente após } \\
\text { o término do trabalho ou quantas vezes forem necessárias. São tomadas } \\
\text { precauções para impedir a contaminação dos alimentos causada por } \\
\text { produtos saneantes, pela suspensão de partículas e pela formação de } \\
\text { aerossóis. }\end{array}$ \\
\hline & $\begin{array}{l}\text { Substâncias odorizantes e ou desodorantes em quaisquer das suas formas } \\
\text { não são utilizadas nas áreas de preparação dos alimentos }\end{array}$ \\
\hline & $\begin{array}{l}\text { Os produtos saneantes utilizados são regularizados pelo Ministério } \\
\text { da Saúde. A diluição, o tempo de contato e modo de uso/aplicação } \\
\text { dos produtos saneantes obedecem às instruções recomendadas pelo } \\
\text { fabricante. Os produtos saneantes são identificados e guardados em local } \\
\text { reservado para essa finalidade. }\end{array}$ \\
\hline & $\begin{array}{l}\text { Os utensílios necessários às operações de higienização são adequados, } \\
\text { estando disponíveis em número suficiente e em bom estado de higiene e } \\
\text { de conservação. Os utensílios utilizados na higienização de instalações são } \\
\text { distintos daqueles usados para higienização das partes dos equipamentos } \\
\text { e utensílios que entrem em contato com o alimento. }\end{array}$ \\
\hline & $\begin{array}{l}\text { Os funcionários responsáveis pela atividade de higienização das } \\
\text { instalações sanitárias usam uniformes apropriados e diferenciados } \\
\text { daqueles utilizados na manipulação de alimentos }\end{array}$ \\
\hline
\end{tabular}




\begin{tabular}{|c|c|}
\hline \multirow{5}{*}{$\begin{array}{l}\text { ABASTECIMENTO } \\
\text { DE ÁGUA }\end{array}$} & Utiliza-se somente água potável para manipulação de alimentos. \\
\hline & $\begin{array}{l}\text { O gelo para utilização em alimentos é fabricado a partir de água potável, } \\
\text { mantido em condição higiênico-sanitária que evite sua contaminação. }\end{array}$ \\
\hline & $\begin{array}{l}\text { O vapor, quando utilizado em contato direto com alimentos ou com } \\
\text { superfícies que entrem em contato com alimentos, é produzido a partir } \\
\text { de água potável e não representa fonte de contaminação. }\end{array}$ \\
\hline & $\begin{array}{l}\text { O reservatório de água é edificado e/ou revestido de materiais que não } \\
\text { comprometam a qualidade da água, conforme legislação específica. Deve } \\
\text { estar livre de rachaduras, vazamentos, infiltrações, descascamentos, } \\
\text { dentre outros defeitos, e em adequado estado de higiene e conservação, } \\
\text { devendo estar devidamente tampado. }\end{array}$ \\
\hline & $\begin{array}{l}\text { O reservatório de água é higienizado, em um intervalo máximo de seis } \\
\text { meses, sendo mantidos registros da operação. }\end{array}$ \\
\hline \multirow{3}{*}{$\begin{array}{l}\text { MANEJO DOS } \\
\text { RESÍDUOS }\end{array}$} & $\begin{array}{l}\text { O estabelecimento dispõe de recipientes identificados e íntegros, de } \\
\text { fácil higienização e transporte, em número e capacidade suficientes } \\
\text { para conter os resíduos. Estão identificados e devidamente forrados com } \\
\text { sacos plásticos. }\end{array}$ \\
\hline & $\begin{array}{l}\text { Os coletores utilizados para deposição dos resíduos das áreas de } \\
\text { preparação e armazenamento de alimentos devem ser dotados de tampas } \\
\text { acionadas sem contato manual. }\end{array}$ \\
\hline & $\begin{array}{l}\text { Os resíduos são frequentemente coletados e estocados em local fechado e } \\
\text { isolado da área de preparação e armazenamento dos alimentos, de forma } \\
\text { a evitar focos de contaminação e atração de vetores e pragas urbanas. }\end{array}$ \\
\hline \multirow{3}{*}{ MANIPULADORES } & $\begin{array}{l}\text { O controle da saúde dos manipuladores é registrado e realizado de acordo } \\
\text { com a legislação específica. }\end{array}$ \\
\hline & $\begin{array}{l}\text { Os manipuladores que apresentarem lesões e/ou sintomas de } \\
\text { enfermidades que possam comprometer a qualidade higiênico-sanitária } \\
\text { dos alimentos são afastados da atividade de preparação de alimentos } \\
\text { enquanto persistirem essas condições de saúde. }\end{array}$ \\
\hline & $\begin{array}{l}\text { Os manipuladores têm asseio pessoal, apresentando-se com uniformes } \\
\text { compatíveis à atividade, conservados e limpos. Os uniformes são trocados, } \\
\text { no mínimo, diariamente e usados exclusivamente nas dependências } \\
\text { internas do estabelecimento. As roupas e os objetos pessoais são } \\
\text { guardados em local específico e reservado para esse fim. }\end{array}$ \\
\hline
\end{tabular}




\begin{tabular}{|c|c|}
\hline \multirow{6}{*}{ MANIPULADORES } & $\begin{array}{l}\text { Os manipuladores lavam cuidadosamente as mãos ao chegar ao trabalho, } \\
\text { antes e após manipular alimentos, após qualquer interrupção do serviço, } \\
\text { após tocar materiais contaminados, após usar os sanitários e sempre que } \\
\text { se fizer necessário. }\end{array}$ \\
\hline & $\begin{array}{l}\text { São afixados cartazes de orientação aos manipuladores sobre a correta } \\
\text { lavagem e antissepsia das mãos e demais hábitos de higiene, em locais } \\
\text { de fácil visualização, inclusive nas instalações sanitárias e lavatórios. }\end{array}$ \\
\hline & $\begin{array}{l}\text { Os manipuladores não fumam, falam, cantam, assobiam, espirram, } \\
\text { cospem, tossem, comem, manipulam dinheiro ou praticam outros } \\
\text { atos que possam contaminar o alimento, durante o desempenho das } \\
\text { atividades. }\end{array}$ \\
\hline & $\begin{array}{l}\text { Os manipuladores usam cabelos presos e protegidos por redes, toucas ou } \\
\text { outro acessório apropriado para esse fim, não sendo permitido o uso de } \\
\text { barba. As unhas são curtas e sem esmalte ou base. Durante a manipulação, } \\
\text { devem ser retirados todos os objetos de adorno pessoal e a maquiagem. }\end{array}$ \\
\hline & $\begin{array}{l}\text { Os manipuladores de alimentos são supervisionados e capacitados } \\
\text { periodicamente em higiene pessoal, em manipulação higiênica dos } \\
\text { alimentos e em doenças transmitidas por alimentos. A capacitação é } \\
\text { comprovada mediante documentação. }\end{array}$ \\
\hline & $\begin{array}{l}\text { Os visitantes cumprem os requisitos de higiene e de saúde estabelecidos } \\
\text { para os manipuladores. }\end{array}$ \\
\hline \multirow{4}{*}{$\begin{array}{l}\text { MATÉRIAS-PRIMAS, } \\
\text { INGREDIENTES E } \\
\text { EMBALAGENS }\end{array}$} & $\begin{array}{l}\text { O serviço de alimentação específica os critérios para avaliação e seleção } \\
\text { dos fornecedores de matérias-primas, ingredientes e embalagens, sendo o } \\
\text { transporte desses insumos realizado em condições adequadas de higiene } \\
\text { e conservação. }\end{array}$ \\
\hline & $\begin{array}{l}\text { A recepção das matérias-primas, dos ingredientes e das embalagens é } \\
\text { realizada em área protegida e limpa. São adotadas medidas para evitar } \\
\text { que esses insumos contaminem o alimento preparado. }\end{array}$ \\
\hline & $\begin{array}{l}\text { As matérias-primas, os ingredientes e as embalagens são submetidos } \\
\text { à inspeção e aprovados na recepção. As embalagens primárias das } \\
\text { matérias-primas e dos ingredientes são íntegras. A temperatura das } \\
\text { matérias-primas e ingredientes que necessitem de condições especiais de } \\
\text { conservação são verificadas nas etapas de recepção e de armazenamento. }\end{array}$ \\
\hline & $\begin{array}{l}\text { Os lotes das matérias-primas, dos ingredientes ou das embalagens } \\
\text { reprovados ou com prazos de validade vencidos são imediatamente } \\
\text { devolvidos ao fornecedor e, na impossibilidade, são devidamente } \\
\text { identificados e armazenados separadamente e são determinadas a } \\
\text { destinação final dos mesmos. }\end{array}$ \\
\hline
\end{tabular}




\begin{tabular}{|c|c|}
\hline \multirow{2}{*}{$\begin{array}{l}\text { MATÉRIAS-PRIMAS, } \\
\text { INGREDIENTES E } \\
\text { EMBALAGENS }\end{array}$} & $\begin{array}{l}\text { As matérias-primas, os ingredientes e as embalagens são armazenados } \\
\text { em local limpo e organizado, de forma a garantir proteção contra } \\
\text { contaminantes. São adequadamente acondicionados e identificados, } \\
\text { sendo que sua utilização deve respeitar o prazo de validade. Para os } \\
\text { alimentos dispensados da obrigatoriedade da indicação do prazo de } \\
\text { validade, é observada a ordem de entrada dos mesmos. }\end{array}$ \\
\hline & $\begin{array}{l}\text { As matérias-primas, os ingredientes e as embalagens são armazenados } \\
\text { sobre paletes, estrados e ou prateleiras, respeitando-se o espaçamento } \\
\text { mínimo necessário para garantir adequada ventilação, limpeza e, quando } \\
\text { for o caso, desinfecção do local. Os paletes, estrados e ou prateleiras são } \\
\text { de material liso, resistente, impermeável e lavável. }\end{array}$ \\
\hline \multirow{7}{*}{$\begin{array}{l}\text { PREPARAÇÃO DO } \\
\text { ALIMENTO }\end{array}$} & $\begin{array}{l}\text { As matérias-primas, os ingredientes e as embalagens utilizados para } \\
\text { preparação do alimento estão em condições higiênico-sanitárias } \\
\text { adequadas e em conformidade com a legislação específica. }\end{array}$ \\
\hline & $\begin{array}{l}\text { O quantitativo de funcionários, equipamentos, móveis e/ou utensílios } \\
\text { disponíveis é compatível com volume, diversidade e complexidade das } \\
\text { preparações alimentícias. }\end{array}$ \\
\hline & $\begin{array}{l}\text { Durante a preparação dos alimentos, são adotadas medidas a fim de } \\
\text { minimizar o risco de contaminação cruzada. É evitado o contato direto ou } \\
\text { indireto entre alimentos crus, semipreparados e prontos para o consumo. }\end{array}$ \\
\hline & $\begin{array}{l}\text { Os funcionários que manipulam alimentos crus realizam a lavagem e a } \\
\text { antissepsia das mãos antes de manusear alimentos preparados }\end{array}$ \\
\hline & $\begin{array}{l}\text { As matérias-primas e os ingredientes caracterizados como produtos } \\
\text { perecíveis são expostos à temperatura ambiente somente pelo tempo } \\
\text { mínimo necessário para a preparação do alimento, a fim de não } \\
\text { comprometer a qualidade higiênico-sanitária do alimento preparado. }\end{array}$ \\
\hline & $\begin{array}{l}\text { Quando as matérias-primas e os ingredientes não forem utilizados em } \\
\text { sua totalidade, são adequadamente acondicionados e identificados com, } \\
\text { no mínimo, as seguintes informações: designação do produto, data } \\
\text { de fracionamento e prazo de validade após a abertura ou retirada da } \\
\text { embalagem original. }\end{array}$ \\
\hline & $\begin{array}{l}\text { Quando aplicável, antes de iniciar a preparação dos alimentos, procede- } \\
\text { se à adequada limpeza das embalagens primárias das matérias-primas e } \\
\text { dos ingredientes, minimizando o risco de contaminação. }\end{array}$ \\
\hline
\end{tabular}




\begin{tabular}{|c|c|}
\hline \multirow{8}{*}{$\begin{array}{l}\text { PREPARAÇÃ } \\
\text { ALIMENTO }\end{array}$} & $\begin{array}{l}\text { O tratamento térmico garante que todas as partes do alimento atinjam a } \\
\text { temperatura de, no mínimo, } 70^{\circ} \mathrm{C} \text { (setenta graus Celsius). Temperaturas } \\
\text { inferiores são utilizadas no tratamento térmico desde que as combinações } \\
\text { de tempo e temperatura sejam suficientes para assegurar a qualidade } \\
\text { higiênico-sanitária dos alimentos. }\end{array}$ \\
\hline & $\begin{array}{l}\text { A eficácia do tratamento térmico é avaliada pela verificação da } \\
\text { temperatura e do tempo utilizados e, quando aplicável, pelas mudanças } \\
\text { na textura e cor na parte central do alimento. }\end{array}$ \\
\hline & $\begin{array}{l}\text { Para os alimentos que são submetidos à fritura, além dos controles } \\
\text { estabelecidos para um tratamento térmico, são aplicadas medidas que } \\
\text { garantam que o óleo e a gordura utilizados não constituam uma fonte } \\
\text { de contaminação química do alimento preparado. }\end{array}$ \\
\hline & $\begin{array}{l}\text { Os óleos e gorduras utilizados são aquecidos a temperaturas não } \\
\text { superiores a } 180^{\circ} \mathrm{C} \text { (cento e oitenta graus Celsius), sendo substituídos } \\
\text { imediatamente sempre que houver alteração evidente das características } \\
\text { físico-químicas ou sensoriais, tais como aroma e sabor, e formação intensa } \\
\text { de espuma e fumaça. }\end{array}$ \\
\hline & $\begin{array}{l}\text { Para os alimentos congelados, antes do tratamento térmico, procede-se } \\
\text { ao descongelamento, a fim de garantir adequada penetração do calor. } \\
\text { Excetuam-se os casos em que o fabricante do alimento recomenda que } \\
\text { o mesmo seja submetido ao tratamento térmico ainda congelado, são } \\
\text { seguidas as orientações constantes da rotulagem. }\end{array}$ \\
\hline & $\begin{array}{l}\text { O descongelamento é conduzido de forma a evitar que as áreas } \\
\text { superficiais dos alimentos se mantenham em condições favoráveis à } \\
\text { multiplicação microbiana. O descongelamento é efetuado em condições } \\
\text { de refrigeração à temperatura inferior a } 5^{\circ} \mathrm{C} \text { (cinco graus Celsius) ou em } \\
\text { forno de microondas quando o alimento for submetido imediatamente } \\
\text { à cocção. }\end{array}$ \\
\hline & $\begin{array}{l}\text { Os alimentos submetidos ao descongelamento são mantidos sob } \\
\text { refrigeração se não forem imediatamente utilizados, não devendo ser } \\
\text { recongelados. }\end{array}$ \\
\hline & $\begin{array}{l}\text { Após serem submetidos à cocção, os alimentos preparados são mantidos } \\
\text { em condições de tempo e de temperatura que não favoreçam a } \\
\text { multiplicação microbiana. Para conservação a quente, os alimentos } \\
\text { são submetidos a temperatura superior a } 60^{\circ} \mathrm{C} \text { (sessenta graus Celsius) } \\
\text { por, no máximo, } 6 \text { (seis) horas. Para conservação sob refrigeração ou } \\
\text { congelamento, os alimentos são previamente submetidos ao processo } \\
\text { de resfriamento. }\end{array}$ \\
\hline
\end{tabular}




\begin{tabular}{|c|c|}
\hline \multirow{5}{*}{$\begin{array}{l}\text { PREPARAÇÃO DO } \\
\text { ALIMENTO }\end{array}$} & $\begin{array}{l}\text { O processo de resfriamento de um alimento preparado é realizado de } \\
\text { forma a minimizar o risco de contaminação cruzada e a permanência do } \\
\text { mesmo em temperaturas que favoreçam a multiplicação microbiana. A } \\
\text { temperatura do alimento preparado é reduzida de } 60^{\circ} \mathrm{C} \text { (sessenta graus } \\
\text { Celsius) a } 10^{\circ} \mathrm{C} \text { (dez graus Celsius) em até duas horas. Em seguida, o } \\
\text { mesmo é conservado sob refrigeração a temperaturas inferiores a } 5^{\circ} \mathrm{C} \\
\text { (cinco graus Celsius), ou congelado a temperatura igual ou inferior a } \\
-18^{\circ} \mathrm{C} \text { (dezoito graus Celsius negativos). }\end{array}$ \\
\hline & $\begin{array}{l}\text { O prazo máximo de consumo do alimento preparado e conservado sob } \\
\text { refrigeração a temperatura de } 4^{\circ} \mathrm{C} \text { (quatro graus Celsius), ou inferior, } \\
\text { é de } 5 \text { (cinco) dias. Quando forem utilizadas temperaturas superiores } \\
\text { a } 4^{\circ} \mathrm{C} \text { (quatro graus Celsius) e inferiores a } 5^{\circ} \mathrm{C} \text { (cinco graus Celsius), o } \\
\text { prazo máximo de consumo é reduzido, de forma a garantir as condições } \\
\text { higiênico-sanitárias do alimento preparado. }\end{array}$ \\
\hline & $\begin{array}{l}\text { Caso o alimento preparado seja armazenado sob refrigeração ou } \\
\text { congelamento, é colocado no invólucro do mesmo, no mínimo, as } \\
\text { seguintes informações: designação, data de preparo e prazo de validade. A } \\
\text { temperatura de armazenamento é regularmente monitorada e registrada. }\end{array}$ \\
\hline & $\begin{array}{l}\text { Quando aplicável, os alimentos que são consumidos crus são submetidos } \\
\text { a processo de higienização, a fim de reduzir a contaminação superficial. } \\
\text { Os produtos utilizados na higienização dos alimentos são regularizados } \\
\text { no órgão competente do Ministério da Saúde e são aplicados de forma } \\
\text { a evitar a presença de resíduos no alimento preparado. }\end{array}$ \\
\hline & $\begin{array}{l}\text { O estabelecimento implementa e mantém documentado o controle e } \\
\text { garantia da qualidade dos alimentos preparados. }\end{array}$ \\
\hline \multirow{3}{*}{$\begin{array}{l}\text { ARMAZENAMENTO } \\
\text { E TRANSPORTE } \\
\text { DO ALIMENTO } \\
\text { PREPARADO }\end{array}$} & $\begin{array}{l}\text { Os alimentos preparados mantidos na área de armazenamento ou } \\
\text { aguardando o transporte estão identificados e protegidos contra } \\
\text { contaminantes. Na identificação consta, no mínimo, a designação do } \\
\text { produto, a data de preparo e o prazo de validade. }\end{array}$ \\
\hline & $\begin{array}{l}\text { O armazenamento e o transporte do alimento preparado, da distribuição } \\
\text { até a entrega ao consumo, ocorre em condições de tempo e temperatura } \\
\text { que não comprometam sua qualidade higiênico-sanitária. A temperatura } \\
\text { do alimento preparado é monitorada durante essas etapas. }\end{array}$ \\
\hline & $\begin{array}{l}\text { Os meios de transporte do alimento preparado são higienizados, sendo } \\
\text { adotadas medidas a fim de garantir a ausência de vetores e pragas } \\
\text { urbanas. Os veículos são dotados de cobertura para proteção da carga, } \\
\text { não transportam outras cargas que comprometam a qualidade higiênico- } \\
\text { sanitária do alimento preparado. }\end{array}$ \\
\hline
\end{tabular}




\begin{tabular}{|c|c|}
\hline \multirow{7}{*}{$\begin{array}{l}\text { EXPOSIÇÃO } \\
\text { AO CONSUMO } \\
\text { DO ALIMENTO } \\
\text { PREPARADO }\end{array}$} & $\begin{array}{l}\text { As áreas de exposição do alimento preparado e de consumação ou } \\
\text { refeitório são mantidas organizadas e em adequadas condições higiênico- } \\
\text { sanitárias. Os equipamentos, móveis e utensílios disponíveis nessas áreas } \\
\text { são compatíveis com as atividades, em número suficiente e em adequado } \\
\text { estado de conservação. }\end{array}$ \\
\hline & $\begin{array}{l}\text { Os manipuladores adotam procedimentos que minimizem o risco de } \\
\text { contaminação dos alimentos preparados por meio da antissepsia das } \\
\text { mãos e pelo uso de utensílios ou luvas descartáveis. }\end{array}$ \\
\hline & $\begin{array}{l}\text { Os equipamentos necessários à exposição ou distribuição de } \\
\text { alimentos preparados sob temperaturas controladas, são devidamente } \\
\text { dimensionados, e estão em adequado estado de higiene, conservação e } \\
\text { funcionamento. A temperatura desses equipamentos é regularmente } \\
\text { monitorada. }\end{array}$ \\
\hline & $\begin{array}{l}\text { O equipamento de exposição do alimento preparado na área de } \\
\text { consumação dispõe de barreiras de proteção que previnam a } \\
\text { contaminação do mesmo em decorrência da proximidade ou da ação } \\
\text { do consumidor e de outras fontes. }\end{array}$ \\
\hline & $\begin{array}{l}\text { Os utensílios utilizados na consumação do alimento, tais como pratos, } \\
\text { copos, talheres, são descartáveis ou, quando feitos de material não } \\
\text { descartável, devidamente higienizados, sendo armazenados em local } \\
\text { protegido. }\end{array}$ \\
\hline & $\begin{array}{l}\text { Os ornamentos e plantas localizados na área de consumação ou refeitório } \\
\text { não constituem fonte de contaminação para os alimentos preparados. }\end{array}$ \\
\hline & $\begin{array}{l}\text { A área do serviço de alimentação onde se realiza a atividade de } \\
\text { recebimento de dinheiro, cartões e outros meios utilizados para o } \\
\text { pagamento de despesas é reservada. Os funcionários responsáveis por } \\
\text { essa atividade não manipulam alimentos preparados, embalados ou não. }\end{array}$ \\
\hline \multirow{3}{*}{$\begin{array}{l}\text { DOGUMENTAÇÃO E } \\
\text { REGISTRO }\end{array}$} & $\begin{array}{l}\text { Os serviços de alimentação dispõem de Manual de Boas Práticas e de } \\
\text { Procedimentos Operacionais Padronizados (POP). Esses documentos estão } \\
\text { acessíveis aos funcionários envolvidos e disponíveis à autoridade sanitária, } \\
\text { quando requerido. }\end{array}$ \\
\hline & $\begin{array}{l}\text { Os POP contêm as instruções sequenciais das operações e a frequência de } \\
\text { execução, especificando o nome, o cargo e ou a função dos responsáveis } \\
\text { pelas atividades. São aprovados, datados e assinados pelo responsável } \\
\text { do estabelecimento. }\end{array}$ \\
\hline & $\begin{array}{l}\text { Os registros são mantidos por período mínimo de } 30 \text { (trinta) dias contados } \\
\text { a partir da data de preparação dos alimentos. }\end{array}$ \\
\hline
\end{tabular}




\begin{tabular}{|c|c|}
\hline \multirow{5}{*}{$\begin{array}{l}\text { DOCUMENTAÇÃO E } \\
\text { REGISTRO }\end{array}$} & $\begin{array}{l}\text { O serviço de alimentação tem POP relacionados aos seguintes itens: a) } \\
\text { higienização de instalações, equipamentos e móveis; b) controle integrado } \\
\text { de vetores e pragas urbanas; c) higienização do reservatório; d) higiene } \\
\text { e saúde dos manipuladores. }\end{array}$ \\
\hline & $\begin{array}{l}\text { Os POP referentes às operações de higienização de instalações, } \\
\text { equipamentos e móveis contêm as seguintes informações: natureza da } \\
\text { superfície a ser higienizada, método de higienização, princípio ativo } \\
\text { selecionado e sua concentração, tempo de contato dos agentes químicos } \\
\text { e/ou físicos utilizados na operação de higienização, temperatura e outras } \\
\text { informações que se fizerem necessárias. Quando aplicável, os POP } \\
\text { contemplam a operação de desmonte dos equipamentos. }\end{array}$ \\
\hline & $\begin{array}{l}\text { Os POP relacionados ao controle integrado de vetores e pragas urbanas } \\
\text { contemplam as medidas preventivas e corretivas destinadas a impedir } \\
\text { a atração, o abrigo, o acesso e/ou a proliferação de vetores e pragas } \\
\text { urbanas. No caso da adoção de controle químico, o estabelecimento } \\
\text { apresenta comprovante de execução de serviço fornecido pela empresa } \\
\text { especializada contratada, contendo as informações estabelecidas em } \\
\text { legislação sanitária específica. }\end{array}$ \\
\hline & $\begin{array}{l}\text { Os POP referentes à higienização do reservatório, mesmo quando } \\
\text { realizada por empresa terceirizada e, neste caso, é apresentado o } \\
\text { certificado de execução do serviço. }\end{array}$ \\
\hline & $\begin{array}{l}\text { Os POP relacionados à higiene e saúde dos manipuladores contemplam as } \\
\text { etapas, a frequência e os princípios ativos usados na lavagem e antissepsia } \\
\text { das mãos dos manipuladores, assim como as medidas adotadas nos casos em } \\
\text { que os manipuladores apresentem lesão nas mãos, sintomas de enfermidade } \\
\text { ou suspeita de problema de saúde que possa comprometer a qualidade } \\
\text { higiênico-sanitária dos alimentos. Especificam-se os exames aos quais os } \\
\text { manipuladores de alimentos são submetidos, bem como a periodicidade de } \\
\text { sua execução. O programa de capacitação dos manipuladores em higiene } \\
\text { é descrito, sendo determinados a carga horária, o conteúdo programático } \\
\text { e a frequência de sua realização, mantendo-se em arquivo os registros da } \\
\text { participação nominal dos funcionários. }\end{array}$ \\
\hline \multirow[b]{2}{*}{ RESPONSABILIDADE } & $\begin{array}{l}\text { O responsável pelas atividades de manipulação dos alimentos é o } \\
\text { proprietário ou funcionário designado, devidamente capacitado, sem } \\
\text { prejuízo dos casos em que há previsão legal para responsabilidade técnica. }\end{array}$ \\
\hline & $\begin{array}{l}\text { O responsável pelas atividades de manipulação dos alimentos é } \\
\text { comprovadamente submetido a curso de capacitação abordando, no mínimo, } \\
\text { os seguintes temas: a) contaminantes alimentares; b) doenças transmitidas } \\
\text { por alimentos; c) manipulação higiênica dos alimentos; d) Boas Práticas. }\end{array}$ \\
\hline
\end{tabular}


A classificação de cada restaurante seguiu os critérios de pontuação estabelecidos no item D da Resolução RDC n⿳ 275/2002 (BRASIL, 2002), ${ }^{8}$ a saber: Grupo 1 (76 a 100\% de atendimento dos itens); Grupo 2 (51 a 75\% de atendimento dos itens); e Grupo 3 (0 a 50\% de atendimento dos itens). Foi classificado também cada um dos 11 blocos da lista de verificação, de acordo com esse critério. As UANs foram denominadas "Unidade 1" e "Unidade 2".

Os dados coletados foram armazenados em planilhas do Microsoft Excel e analisados de forma descritiva, com auxílio do no programa estatístico Stata, versão 9.1 (Stata Corp., College Station, Estados Unidos).

\section{Resultados e Discussão}

Em relação ao atendimento aos itens propostos na lista de verificação, o percentual de adequação na Unidade 1 foi igual a 71,81 \% e na Unidade 2 foi 76,36; sendo classificados no Grupo 2 e Grupo 1 , respectivamente.

A Unidade 1 distribui 2.000 refeições por dia, sendo que o sistema de distribuição com atendimento porcionado de todas as preparações. A Unidade 2 distribui em média 5.000 refeições por dia, com maior número de refeições servido no almoço. O sistema de distribuição das refeições na unidade era do tipo self service, sendo que, o prato principal/ opção, suco e sobremesa eram porcionados.

Na Figura 1 e 2, estão dispostos os percentuais de adequação e inadequação às boas práticas de manipulação de alimentos, por blocos, nas UANs avaliadas. 


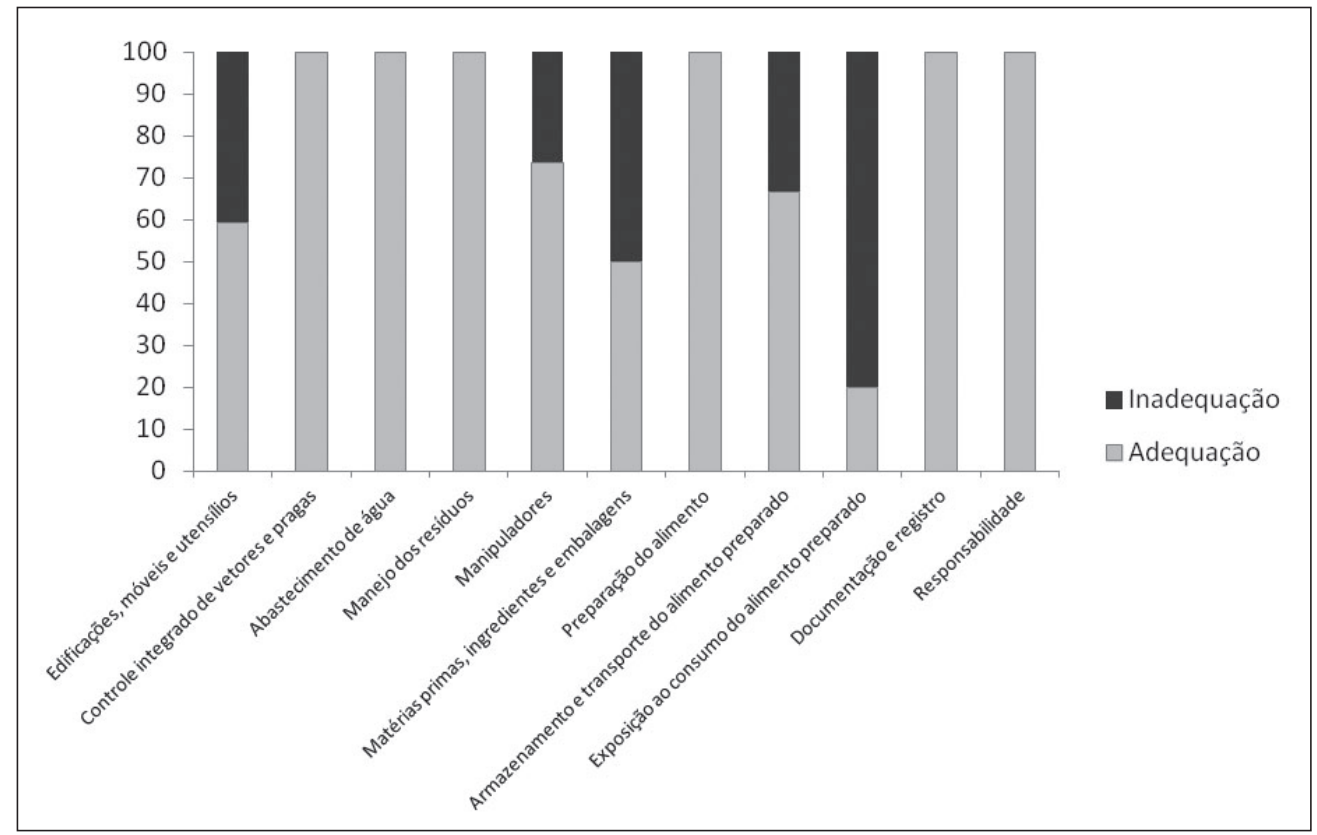

Figura 1. Percentual de adequação e inadequação às boas práticas de manipulação de alimentos na Unidade 1. Vitória-ES, 2013.

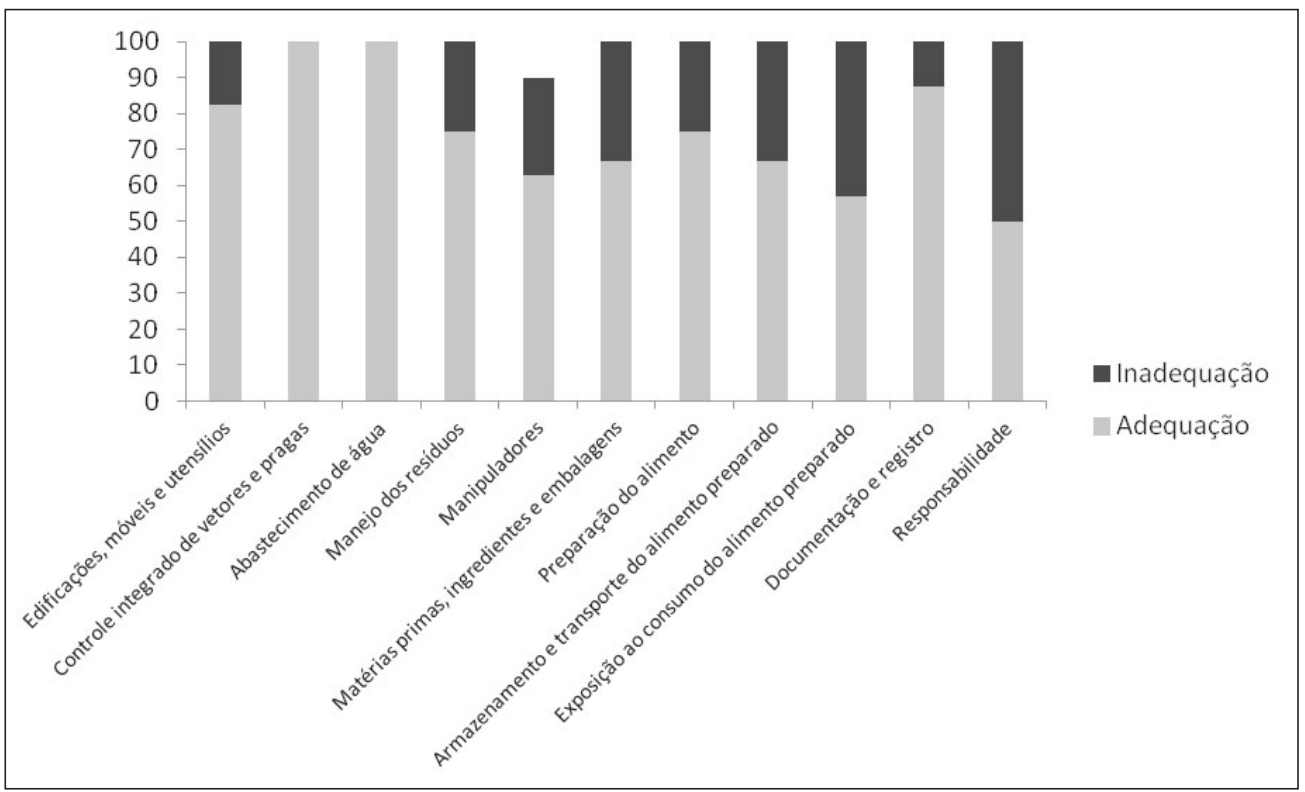

Figura 2. Percentual de adequação e inadequação às boas práticas de manipulação de alimentos na Unidade 2. Vitória-ES, 2013. 


\section{Edificações, móveis e utensílios}

Na Unidade 1, o dimensionamento da edificação e das instalações não estava compatível com todas as operações, podendo contribuir para o risco de contaminação cruzada, já que o local era pequeno e os procedimentos eram realizados próximos uns dos outros. Na Unidade 2 esse problema não ocorreu, devido à maior adequação do dimensionamento. As principais inadequações encontradas neste bloco estão relacionadas às instalações físicas e ventilação. Dentre as inadequações registradas neste bloco, nas duas unidades avaliadas, destacam-se: existência de portas sem fechamento automático, iluminação de baixa qualidade, falta de manutenção dos equipamentos utilizados no preparo, bem como pisos e paredes em péssimo estado de conservação.

Inconformidades como objetos em desuso (equipamentos danificados, vasilhames e utensílios em péssimo estado de conservação), ausência de sabonete líquido inodoro antisséptico ou sabonete líquido inodoro e produto antisséptico nos lavatórios e toalhas de papel brancas também foram registradas. Objetos em desuso podem aumentar a chance de contaminação, devido à possibilidade de desgaste do material e assim, permitir o acúmulo de resíduos de alimentos. Situações semelhantes foram evidenciadas por São José e Pinheiro-Sant'Ana ${ }^{9}$ em UANs escolares.

Em estudo realizado no município de Duque de Caxias, foi possível observar que todas as UANs apresentaram inconformidades relacionadas a estrutura física, o que levava a cruzamento de áreas sujas e limpas podendo levar a contaminação dos alimentos ${ }^{9}$

Segundo a RDC n⿳0 216/2004, ${ }^{7}$ as instalações físicas como piso, parede e teto devem possuir revestimento liso, impermeável e lavável; portas e janelas devem ser mantidas ajustadas aos batentes e devem existir lavatórios exclusivos para a higiene das mãos na área de manipulação, em posições estratégicas. Na Unidade 1 foram observadas falhas quanto às condições do piso e das paredes, tanto no setor de preparo dos alimentos quanto nas instalações sanitárias, que apresentavam vários pontos quebrados e estufados.

Fonseca et al. ${ }^{11}$ relataram a importância da adequação das edificações, instalações, equipamentos, móveis e utensílios para suporte e garantia da implementação das boas práticas e qualidade dos alimentos preparados em serviços de alimentação. Quando as edificações e instalações são projetadas corretamente, permitem a ordenação do fluxo de produção e evitam cruzamentos em todas as etapas da preparação de alimentos, contribuindo para as operações de manutenção, limpeza e desinfecção.

Foram observadas, na Unidade 1, inadequações como a guarda de saneantes em local inadequado, não havendo materiais em número suficiente para realização da limpeza e uso de uniformes impróprios para execução da atividade. Foi constado que não havia sanitizantes, e a higienização estava sendo realizada de forma inadequada. Por consequência, as superfícies 
apresentavam condições impróprias para o preparo dos alimentos. Rossi, ${ }^{12} \mathrm{em}$ estudo realizado em Belo Horizonte, considerou insatisfatório o resultado da maioria dos restaurantes comerciais avaliados, contabilizando menos do que $50 \%$ de adequação para este bloco.

Na Unidade 2 foi observado que não há registros das operações de limpeza e falhas no procedimento de diluição dos saneantes utilizados. Segundo a RDC no 216/2014, ${ }^{7}$ os produtos saneantes utilizados devem estar regularizados pelo Ministério da Saúde. A diluição, o tempo de contato e modo de uso/aplicação dos produtos saneantes devem obedecer às instruções recomendadas pelo fabricante. Além disso, os funcionários responsáveis pela atividade de higienização das instalações sanitárias devem utilizar uniformes apropriados e diferenciados daqueles utilizados na manipulação de alimentos.

\section{Controle integrado de pragas}

Em ambas as unidades, os itens avaliados estavam em conformidade, diferentemente do evidenciado por Gomes et al. ${ }^{13}$ Os autores detectaram que 92,3\% das unidades avaliadas não possuíam controle integrado de pragas e vetores urbanos. Dessa forma, o resultado encontrado nas unidades 1 e 2 do presente estudo demonstra que estas têm adotado medidas com intuito de impedir a atração, o abrigo, o acesso e ou proliferação de vetores e pragas urbanas, garantindo a segurança dos usuários. O CIP é indispensável na prevenção de toxinfecções alimentares, devendose considerar também o sentimento de repulsa que a presença de animais causa nos usuários, chegando a comprometer a idoneidade do estabelecimento e dos seus responsáveis. Geralmente, a presença de pragas está relacionada ao desconhecimento de medidas preventivas e corretivas do ambiente, falta de treinamento, além de um planejamento estrutural deficiente ${ }^{14}$.

\section{Abastecimento de água}

Nas unidades, houve $100 \%$ de adequação aos itens avaliados, sendo eles o uso de água potável para manipulação de alimentos, uso de gelo feito a partir de água potável e reservatório de água integro e em ótimo estado de conservação. As unidades apresentavam Procedimentos Operacionais Padronizados para controle de potabilidade da água. É importante recordar que a água é utilizada na preparação dos alimentos, como um ingrediente, e também como coadjuvante na higienização de superfícies e alimentos, por isso é fundamental que seja de boa qualidade. O controle de qualidade da água para qualquer uso na produção de alimentos é necessário para evitar possíveis riscos à saúde dos consumidores dos produtos comercializados. ${ }^{15}$ 


\section{Manejo de resíduos}

Não foram detectadas inconformidades na Unidade 1, entretanto, na Unidade 2 foi observado que os recipientes para guarda do lixo não estavam identificados e devidamente forrados com sacos plásticos. Rossi ${ }^{12}$ observou que nos restaurantes avaliados as condições de manejo eram precárias e inadequadas, sendo que apenas $33,3 \%$ dos itens neste bloco foram atendidos.

O lixo é uma fonte de contaminação a ser controlada devido pelo fato de restos de alimentos favorecerem o aparecimento de vetores e pragas. De acordo com a RDC nํ 216/2004, ${ }^{7}$ os resíduos devem ser frequentemente coletados e estocados em local fechado e isolado da área de preparação dos alimentos, para evitar focos de contaminação e atração de vetores e pragas urbanas.

\section{Manipuladores}

Para a avaliação de manipuladores, nota-se que as Unidades 1 e 2 apresentaram percentuais similares de inconformidade (27\%). O mesmo fora evidenciado por São José et al. ${ }^{16}$ em UANs do município de Contagem-MG. Nas duas unidades não eram realizados exames periódicos, sendo que o responsável por um dos estabelecimentos relatou que são feitos apenas exames para a admissão e para a demissão. Na Unidade 1, os manipuladores usavam roupas pessoais no horário de trabalho devido a atrasos na compra de uniformes. A garantia de roupas apropriadas para o uso no estabelecimento é importante para evitar contaminantes que podem estar presentes na roupa de uso pessoal. ${ }^{18} \mathrm{Na}$ Unidade 2, não havia local apropriado para guarda de objetos pessoais e dessa forma, os manipuladores guardavam pertences como celulares e chaves nos bolsos ou pendurados nas roupas. Foram observados, ainda nessa unidade, hábitos inadequados como falar e tossir durante a manipulação dos alimentos.

As não conformidades encontradas foram semelhantes às observadas no estudo de Oliveira et al., ${ }^{18}$ no qual os manipuladores falavam e cantavam durante a manipulação dos alimentos, e comiam dentro do local de produção. Todas os fatos mencionados anteriormente estão em desacordo com o proposto na RDC no 216/2004. ${ }^{7}$ Segundo Marchi et al., ${ }^{17}$ é importante considerar a possibilidade de o manipulador de alimentos ser um portador assintomático, ou seja, representar uma fonte de transmissão e possivelmente propagar patógenos para os alimentos por meio das mãos contaminadas.

A manipulação de alimentos é um fator que, caso não seja controlado, pode ser responsável por desencadear contaminações e afetar a segurança dos alimentos. ${ }^{14}$ Além disso, a identificação precoce da ocorrência de contaminantes em manipuladores pode contribuir para a prevenção da contaminação de alimentos. ${ }^{16}$ 
Na Unidade 2, não havia nenhum registro de treinamento de manipuladores de alimentos. Segundo a RDC no 216/2004, ${ }^{7}$ os manipuladores necessitam ter asseio pessoal, com uniformes compatíveis com a atividade, conservados e limpos. Além disso, os manipuladores de alimentos devem ser vistoriados e capacitados periodicamente em higiene pessoal, em manipulação higiênica dos alimentos e em doenças transmitidas por alimentos.

\section{Matérias-primas, ingredientes e embalagens}

Em relação a matéria-prima, ingredientes e embalagens, observa-se que a Unidade 1 apresentou mais itens em inconformidade (50\%). No geral, os dois estabelecimentos não apresentavam organização das matérias-primas, de forma a garantir proteção contra contaminantes, indicação do prazo de validade bem como a ordem de entrada e saída. Na Unidade 2 , os alimentos in natura eram armazenados em caixotes de madeira, sem higienização e não estavam dispostos distantes das paredes.

Reolon e Silva ${ }^{20}$ relataram, em estudo com seis restaurantes em Medianeira-PR, que na maioria dos estabelecimentos o armazenamento da matéria-prima era realizado de forma inadequada, com estocagem em lugares impróprios, junto com material de limpeza, no chão, em locais escuros e sem ventilação. Na Unidade 1, a recepção era realizada em área aberta e sem qualquer tipo de controle durante o recebimento (peso, condições da embalagem, temperatura).

A legislação vigente recomenda que tanto o local de recepção como de armazenamento sejam limpos e protegidos, para garantir a proteção contra contaminantes, e que a matéria-prima seja armazenada sobre paletes, prateleiras feitas de material liso e resistente, com espaçamentos que garantam a adequada ventilação e limpeza, quando necessário. ${ }^{6}$

De acordo com Cardoso et al.," ${ }^{21}$ na cadeia produtiva de alimentos, a obtenção da matéria-prima de boa qualidade, com a procedência garantida pelos órgãos de inspeção, é considerada requisito para a garantia da qualidade e da inocuidade do produto final, e está relacionada à saúde dos comensais uma vez que alimentos de procedência indeterminada não passam por inspeção sanitária ou registro em órgãos públicos, procedimento que visa ao controle dos produtos e têm o intuito de garantir que o alimento esteja próprio para o consumo.

No estudo de Campos et al. ${ }^{22}$ em restaurantes do tipo self-service no município de Alfenas-MG, também foram encontrados elevados percentuais de não conformidades relacionadas aos alimentos, como armazenamento em local e sob temperatura inadequada. Reolon e Silva ${ }^{22}$ relataram, em estudo com seis restaurantes em Medianeira-PR, que na maioria dos estabelecimentos o armazenamento da matéria-prima era realizado de forma inadequada, com estocagem em lugares impróprios, junto com material de limpeza, no chão, em locais escuros e sem ventilação. 


\section{Preparação do alimento}

Diferentemente da Unidade 1, a Unidade 2 apresentou itens em inconformidade (25\%), tendo sido observadas várias falhas, como inadequação de temperatura durante o emprego dos tratamentos térmicos, ausência de controle do binômio tempo-temperatura durante a distribuição de alimentos e ausência de controle de temperatura durante a utilização de óleos e gorduras.

As mesmas inconformidades foram observadas por São José e Pinheiro-Sant'Ana ${ }^{9} \mathrm{em}$ unidades de alimentação escolar. A simples presença de termômetros visíveis nos balcões pode ser um aliado importante no quesito "controle da temperatura de distribuição", pois possibilita também a observação pelos clientes, induzindo os responsáveis pelo preparo das refeições a dispensar maior atenção a este fator. ${ }^{24}$

\section{Armazenamento e transporte do alimento preparado}

Nenhuma das unidades avaliadas realizava controle do tempo e temperatura dos alimentos durante o tempo de espera para a distribuição. A Unidade 2 fornecia refeição transportada, porém não realizava controle de temperatura antes do transporte e no momento que os alimentos chegavam à outra unidade.

Monteiro et al., ${ }^{25}$ ao avaliarem as temperaturas de armazenamento e de distribuição de alimentos em restaurantes comerciais localizados numa instituição pública de ensino de Belo HorizonteMG, observaram que para as preparações frias, ocorreram inadequações em 100,0\% (n=11) dos restaurantes avaliados e para as preparações quentes, observou-se que apenas em um restaurante apresentava valores adequados de temperatura.

O binômio "tempo e temperatura" é um instrumento de controle de qualidade da produção de refeições de suma importância, pois preparações quentes e preparações refrigeradas expostas a temperaturas inadequadas durante longos períodos podem favorecer a multiplicação dos microorganismos. $^{25}$

\section{Exposição ao consumo do alimento preparado}

Nas duas unidades avaliadas, os balcões de distribuição não tinham proteção, bem como os utensílios utilizados para consumação dos alimentos, sendo que estes ficavam sobre bancadas de apoio. Os equipamentos necessários para distribuição e exposição dos alimentos preparados não apresentavam temperatura regularmente monitorada. 
O principal objetivo dos balcões térmicos durante a distribuição dos alimentos é fornecer as preparações em temperatura agradável, além de manter condição segura do ponto de vista microbiológico. Para maior segurança no tempo de exposição, é necessário que o equipamento de distribuição esteja sob temperatura controlada, em adequado estado de conservação e funcionamento. ${ }^{26} \mathrm{~A}$ ausência desse controle de temperatura dos alimentos compromete a qualidade das preparações ofertadas, tornando um fator predisponente para as doenças ocasionados por patógenos veiculados por alimentos. ${ }^{27}$

\section{Documentação e registro}

A Unidade 1 apresentou adequação quanto ao Manual de Boas Práticas e Procedimentos Operacionais Padronizados, sendo que esses documentos estavam acessíveis aos funcionários envolvidos e disponíveis para consulta.

A Unidade 2 apresentou inadequação quanto aos registros de treinamento dos programas de capacitação dos manipuladores em boas práticas. A Resolução preconiza que os serviços de alimentação devam estabelecer as boas práticas para garantir as condições higiênico-sanitárias do alimento preparado. ${ }^{7}$ Vila et al. ${ }^{28}$ avaliaram unidades de alimentação escolar e verificaram que $100 \%$ se encontravam com inadequações quanto ao item "documentação e registro".

\section{Responsabilidade}

A Unidade 1 apresentava quatro profissionais nutricionistas para acompanhamento de todo o processo de produção das refeições e havia registros que indicavam o envolvimento dos responsáveis técnicos na realização de capacitações dos manipuladores de alimentos. Na Unidade 2, o treinamento recebido pelo responsável pelas atividades de manipulação dos alimentos não se encontrava devidamente registrado.

De acordo com a RDC no 216/2004, os responsáveis pelas atividades de manipulação de alimentos devem ser submetidos a curso de capacitação em que sejam abordados no mínimo os seguintes temas: contaminantes alimentares, doenças transmitidas por alimentos, manipulação higiênica dos alimentos e boas práticas. ${ }^{7} \mathrm{~A}$ alta adequação registrada nas unidades pode estar relacionada a presença do profissional nutricionista nos locais.

Vila et al..$^{28}$ corroboraram este achado e mencionaram que as escolas possuíam um responsável técnico nutricionista que capacitava periodicamente os manipuladores em temas relacionados à higiene de alimentos. Já em restaurantes populares no estado do Rio de Janeiro, Melo et al., ${ }^{29}$ 
apesar da existência de capacitação dos manipuladores, observaram que estas muitas vezes eram insuficientes para melhorar o conhecimento.

\section{Conclusão}

As unidades foram classificadas no Grupo 1 e Grupo 2, indicando alto percentual de adequação aos itens avaliados. Entretanto, diversas inadequações foram encontradas nos estabelecimentos avaliados, dentre as quais más condições das edificações, instalações, manipulação e organização das atividades. As Unidades 1 e 2 apresentaram inadequações semelhantes, sendo então necessárias melhorias nas condições estruturais e de higienização destes locais, quanto às condições das matérias-primas e em relação às condições de exposição do alimento preparado, sendo que este último apresentou pior percentual de adequação nas duas unidades.

A presença do responsável técnico capacitado é de extrema importância para a realização e manutenção das boas práticas de higiene, porém a dependência dos recursos financeiros muitas vezes impossibilita a atuação de forma adequada, tornando a realização dos procedimentos debilitada por falta de equipamentos, sanitizantes e quantitativo de funcionários, que são de fundamental importância para a realização dos procedimentos de preparo dos alimentos.

Este estudo permitiu demonstrar que a aplicação de uma ferramenta simples, como a lista de verificação, permite avaliar as condições higiênico-sanitárias de unidades que preparam refeições e, a partir das observações, buscar estratégias para correção das falhas.

\section{Referências}

1. Organização Mundial de Saúde. Foodborne disease: a focus for health education. Geneva: World Health Organization; 2000.

2. Associação Brasileira de Refeições Coletivas. Mercado Real. São Paulo. [acesso em : 07 mar 2015]. Disponível em: [http://www.aberc.com.br/mercadoreal.asp?IDMenu=21].

3. Teixeira SMFG, Oliveira, ZMC, Rego JC, Biscontini TMB. Administração aplicada a unidades de alimentação e nutrição. São Paulo: Atheneu; 1990.

4. Ramos MLM, Scatena MF, Ramos MIL. Qualidade higiênico-sanitária de uma unidade de alimentação e nutrição institucional de Campo Grande,MS. Hig. Aliment., 2008; 22(164):25-31.

5. Cunha FMF, Magalhães MBH, Bonnas DS. Desafios da gestão da segurança dos alimentos em unidades de alimentação e nutrição no Brasil: uma revisão. Revista de Comportamento, Cultura e Sociedade, 2012; 1(2):4-14. 
6. Bas M, Ersun AS, Kivanc G. The evaluation of food hygiene knowledge, attitudes, and practices of food handlers in food businesses in Turkey. Food Control. 2006; 17(4):317-22.

7. Brasil, Resolução RDC n 216, de 15 de setembro de 2004. Dispõe sobre o regulamento técnico de boas práticas para serviço de alimentação. Diário oficial [da] República Federal do Brasil: Brasília, DF, 16 set. 2004.

8. Brasil. Resolução RDC n ${ }^{\circ} 275$, de 21 de outubro de 2002. Dispõe sobre o Regulamento Técnico de Procedimentos Operacionais Padronizados aplicados aos Estabelecimentos Produtores/ Industrializadores de Alimentos e a Lista de Verificação das Boas Práticas de Fabricação em Estabelecimentos Produtores/Industrializadores de Alimentos. D.O.U. - Diário Oficial da União; Poder Executivo, de 23 de outubro de 2003.

9. São José JFB, Pinheiro-Sant’Ana HM. Avaliação das boas práticas de manipulação em unidade de alimentação escolar. Nutrire: Rev Soc Bras Alim Nutr. 2008; 33(3):123-38.

10. Silva DO, Oliveira EA, Braga GA, Costa GF, Feijó TS, Cardozo SV. Reconhecimento dos riscos ambientais presentes em unidades de alimentação e nutrição no município de Duque de Caxias, RJ. Saúde \& Amb.,2008; 3(2):1-6.

11. Fonseca MP, Manfridrini LA, São José JFB, Tomazini APB, Martini HSD, Ribeiro RCL, et al. Avaliação das condições físico-funcionais de restaurantes comerciais para Implementação das boas práticas. Alim. Nutr., 2010, 21(2):251-257.

12. Rossi CF. Condições higiênico-sanitárias de restaurantes comerciais do tipo self service de Belo Horizonte-MG. [Dissertação]. Belo Horizonte: Universidade Federal de Minas Gerais; 2006.

13. Gomes, NAAA; Campos, MRH; Monego, ET. Aspectos higiênico-sanitários no processo produtivo dos alimentos em escolas públicas do Estado de Goiás, Brasil. Rev. Nutr. 2012; 25 (1):473-485.

14. Silva Junior EA. Manual de controle higiênico-sanitário em serviços de alimentação. 7 ed. São Paulo: Varela; 2014.

15. Andrade NJ. Higiene na indústria de alimentos. São Paulo: Varela; 2008.

16. São José JFB, Coelho AIM, Ferreira KR. Avaliação das boas práticas em unidade de alimentação e nutrição no município de Contagem-MG. Alim. Nutr., 2011; 22(3):479-487.

17. Marchi DM, Baggio N, Teo CRPA, Busato MA. Ocorrência De Surtos de doenças transmitidas por alimentos no Município de Chapecó, Estado de Santa Catarina, Brasil, no período de 1995 a 2007. Epidemiol. Serv. Saúde, 2011; 20(3):401-407.

18. Bramorski A, Konkevitz D, Souza FO, Crescencio TM, Santos RC Programa de combate à fome do município de Joinville-SC: diagnóstico higiênico-sanitário de cozinhas comunitárias. Hig. Aliment., 2004;18(124):50-53.

19. Oliveira MN, Brasil ALD, Taddei JAAC. Avaliação das condições higiênico-sanitárias das cozinhas de creches públicas e filantrópicas. Ciência \& Saúde Coletiva, 2008,13(3):1051-1060.

20. Reolon CA, Silva SM. Condições higiênico-sanitárias de restaurantes do município de Medianeira, PR. Hig. Aliment, 2009, 23 (174/175):52-56. 
21. Cardoso RCV, Góes JAW, Almeida RCC, Guimarães AG, Barreto DL, Silva SA, et al. Programa nacional de alimentação escolar: há segurança na produção de alimentos em escolas de Salvador (Bahia). Rev Nutr. 2010; 23(5):801-11.

22. Campos MCB, Nicodemo TC, Weber ML. Boas práticas em restaurantes do tipo self - service: situação no município de Alfenas - MG. Hig Alim, 2013; 27(222/223):51-55.

23. Reolon CA, Silva SM. Condições higiênico-sanitárias de restaurantes do município de Medianeira, PR. Hig Alim, 2009; 23(174/175):52-56.

24. Momesso A.P. Levantamento das temperaturas de distribuição de alimentos, durante o período de serviço de bufê, em restaurantes self-service do município de São Paulo e pesquisa de agentes patogênicos e indicadores de higiene. [Dissertação] : São Paulo :Faculdade de Saúde Pública, Universidade de São Paulo; 2002.

25. Monteiro MAM, Ribeiro RC, Fernandes BDA, Sousa JFR, Santos LM. Controle das temperaturas de armazenamento e de distribuição de alimentos em restaurantes comerciais de uma instituição pública de ensino. Demetra; 2014; 9(1); 99-106.

26. Rodrigues FA, Nascimento DA, Cavichioli D, Souza AM. Identificação de pontos críticos de controle de preparações protéicas, em uma unidade de alimentação e nutrição. Hig Alim. 2010; 25 (1):192/193.

27. São José JFB. Contaminação microbiológica em serviços de alimentação. Nutrire: Rev Soc Bras Alim Nutr., 2012; 37(1):78-92.

28. Vila CVD, Silveira JT, Almeida LC. Condições higiênico-sanitárias de cozinhas de escolas públicas de Itaqui, Rio Grande do Sul, Brasil. Vig Sanit Debate 2014; 2(2): 67-74.

29. Melo AG, Gama MP, Marin VA, Colares LGT. Conhecimento dos manipuladores de alimentos sobre boas práticas nos restaurantes públicos populares do Estado do Rio de Janeiro. Braz J Food Technol. 2010:13(1):60-8. 